\title{
Time budgets and habitat use of White-naped Cranes Grus vipio in the Ulz river valley, north- eastern Mongolia during the breeding season
}

\author{
UTE BRADTER, SUNDEV GOMBOBAATAR, CHULUUNBAATAR \\ UUGANBAYAR, TRACY E. GRAZIA and KLAUS-MICHAEL EXO
}

\begin{abstract}
Summary
Habitat loss and degradation are critical threats for the globally threatened White-naped Crane Grus vipio. We estimated the size of the area used per day and the time budgets of parental and non-parental White-naped Crane pairs in north-eastern Mongolia during 2000 and 2001. Six parental crane pairs used an area of $11-155$ ha per day. The maximum distance of a focal parental crane from the roosting-site was 3,030 m. Habitat conservation measures for breeding Whitenaped Cranes need to be targeted to within at least $3 \mathrm{~km}$ of the roosting-site or nest-site. Parental cranes spent $79.6 \pm 4.8 \%$ of the daylight period foraging and had reduced preening and resting behaviour to $4.4 \pm 1.9 \%$. Pairs without juveniles showed a pronounced period of resting and preening behaviour during midday, which was absent in parental cranes. This indicates that parental cranes may be time-stressed. We conclude that increases in feeding-related activities (e.g. caused by a decrease in food availability) are likely to be at the expense of parental vigilance. Conversely, increases in vigilance (due to e.g. increased disturbance) may have a negative impact on feeding-related activities. Both increases can potentially negatively affect reproductive success in this Vulnerable species.
\end{abstract}

\section{Introduction}

The White-naped Crane Grus vipio is globally threatened (Vulnerable fulfilling criteria Azce +3 ce; IUCN 2006). Mongolia is an important breeding area for the species (Goroshko and Tseveenmyadag 2001, 2002, Gombobaatar 2002a, b, Bradter et al. 2005). In Mongolia, Whitenaped Cranes nest in river valleys, along lake edges and in other wetlands, often in the vicinity of pastoral families. Habitat loss and degradation throughout the breeding range are critical threats to the species (Meine and Archibald 1996, BirdLife International 2001). In Mongolia, plans for large-scale agricultural, industrial and infrastructural development and overgrazing by livestock are particularly likely to be detrimental to the breeding population (BirdLife International 2003).

For effective conservation measures, a sound understanding of the biology and ecology of the species is paramount. Studies carried out in China (e.g. Li Chunyuan et al. 1991, Li Peixun et al. 1991, Su et al. 1991, Yuan and Li 1991), Russia and Mongolia (e.g. Fujita et al. 1994, Bold et al. 1995, Dugintsov and Pankin 1995, Gombobaatar and Sumiya 1998, Smirenski 1999, Tseveenmyadag and Goroshko 2001, Goroshko and Tseveenmyadag 2001, 2002, Gombobaatar 2002a, b, Goroshko 2002, Bradter et al. 2005) have provided valuable information on numbers and distribution of White-naped Cranes during the breeding season as well as on breeding behaviour, breeding success and nest-site locations. However, much basic information, for example on foraging habitats, is still not available. 
To allow targeting of conservation measures, it is important to know the spatial requirements of White-naped Crane pairs. Very few attempts to estimate the size of White-naped Crane territories have been made (e.g. Su et al. 1991, Li Peixun et al. 1991). To our knowledge there is no estimate of the size of the daily foraging area or information on its position in relation to the roosting-site available. Neither are habitat requirements of White-naped Cranes on their daily foraging area known. Time budget studies are also an appropriate tool to assess the quality of a particular area and can indicate factors limiting a population (e.g. Exo 1992). They can indicate whether time, food availability and/or predation pressure are limiting factors and in doing so can provide information facilitating the development of conservation strategies.

Time budget studies on Eurasian Cranes Grus grus have shown a bimodal activity pattern. A foraging peak in the morning and afternoon separated by a period of preening behaviour during midday has been found in summering (Wilkening 1999) and wintering Eurasian Cranes (Alonso and Alonso 1992). However, during a more demanding winter of scarce food supply, this pattern almost disappeared (Melo et al. 1999). Parental cranes spend more time being vigilant than nonparental cranes (Nowald 2001) even whilst in the wintering area (Alonso and Alonso 1993). A comparison of the time spent foraging by parental and non-parental birds may indicate whether parental birds are likely to be able to tolerate or compensate for additional pressures (e.g. increased disturbance, decreased food availability) without affecting reproductive success.

Therefore, the main aims of our study were: (a) to obtain time budgets and behaviour patterns for White-naped Crane pairs during the chick-rearing period to assess whether or not parental cranes are time-stressed; (b) to provide data on the size and habitat structure of the daily used area to determine which areas need to be targeted for conservation measures for the species.

\section{Study area and methods}

\section{Study area}

The study area covers $270 \mathrm{~km}$ of the Ulz river basin and the nearby lake Galuut Nuur $\left(48^{\circ} 51^{\prime} \mathrm{N}\right.$, $112^{\circ} 6^{\prime} \mathrm{E}-49^{\circ} 41^{\prime} \mathrm{N}, 115^{\circ} 19^{\prime} \mathrm{E}$ ) (Figure 1 ). The Ulz river basin is listed as a key breeding area for the White-naped Crane (Meine and Archibald 1996). It is located in Khentii and Dornod Aimag (Provinces) of north-eastern Mongolia. Altitude of the study area varies between $640 \mathrm{~m}$ and $1,000 \mathrm{~m}$. The river basin is mostly open with only a few willow trees (Salix sp.). It is largely dominated by typical wetland vegetation (Cyperaceae, Juncaceae and reed Phragmites australis syn communis) interspersed with seasonal and permanent water bodies (flooded areas and ponds). Scattered along the river basin are the winter and summer as well as year-round homes of pastoral families. Cattle, horses and camels graze both the river basin and the adjacent steppe while sheep and goats keep to the steppe. Two villages, Bayan-Uul $\left(49^{\circ} 7^{\prime} \mathrm{N}, 112^{\circ} 41^{\prime} \mathrm{E}\right)$ and Dashbalbar ( $\left.49^{\circ} 33^{\prime} \mathrm{N}, 114^{\circ} 24^{\prime} \mathrm{E}\right)$ are situated in the study area. Parts of Mongol Daguur Strictly Protected Area and Ugtam Nature Reserve are also included. Mongol Daguur Strictly Protected Area is an IBA (BirdLife International 2004), Ramsar site, North East Asian Crane Network site and part of the trilateral Dauria International Reserve of China, Russia and Mongolia (Anonymous 1998). The Ulz river basin has localized high concentrations of breeding pairs. In 2001, 42 territorial pairs were recorded in the study area (Bradter et al. 2005). Fieldwork was carried out from May to August in 2000 and 2001.

\section{Selection of focal pairs}

Locations of pairs were determined by searching the river basin with telescopes and binoculars from nearby hills (see Bradter et al. 2005). Focal pairs were selected in areas allowing the observation of daytime activities simultaneously from two hill observation points. Bird locations obtained by triangulation are most accurate for angles close to $90^{\circ}$ and we tried to select pairs in areas that allowed this. Chick age was estimated by assessing chick size in comparison with 


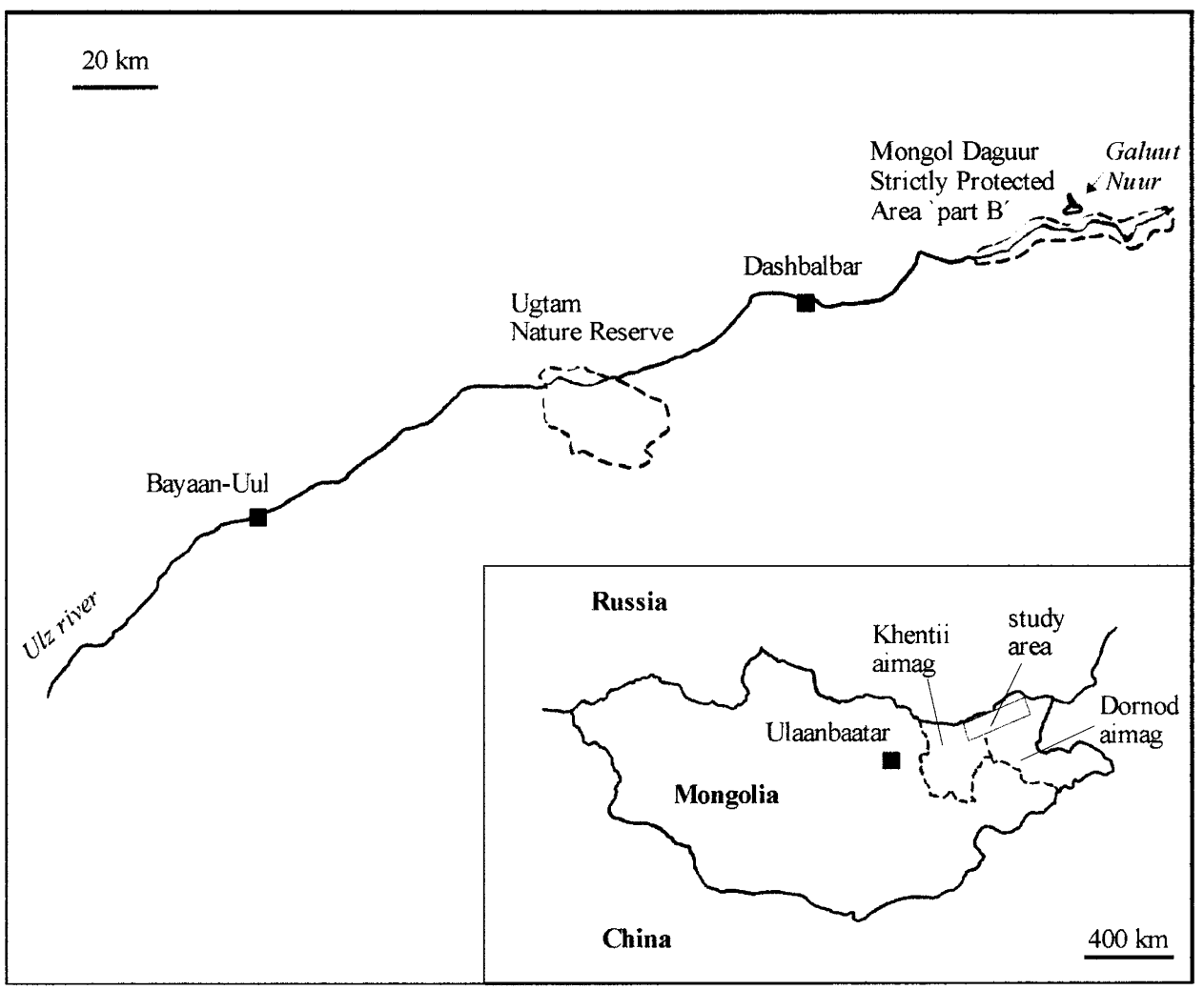

Figure 1 . The study area at the Ulz river and its location in north-eastern Mongolia. Broken lines denote protected areas.

estimated hatching date obtained from egg flotation tests based on data from Florida Sandhill Cranes Grus canadensis pratensis (Fisher and Swengel 1991). Five pairs with chicks were selected in both years and six pairs without chicks in 2000. In 2001, observations of four focal pairs were carried out at an approximate chick age of 15 days and (after the death of the offspring of one pair) of three pairs at an approximate chick age of 30,55 and 65 days.

\section{Focal pair observation}

Behaviour and location of both adults of a pair were recorded every 10 minutes throughout a full observation day (focal sampling, instantaneous time sampling; Martin and Bateson 1986). In 2001, continuous observations were carried out from dawn to dusk. In 2000, observations were allowed to start at any time of day and were continued at dawn on a following day, until a full observation day was covered. If visibility allowed, we recorded the time difference to sunrise and sunset of the first pair partner leaving from or arriving at the roosting-site.

Behaviour was recorded in the following categories: foraging, preening, resting, locomotion, standing, other (alarm, brooding, aggression), and as 'out of sight' when a focal bird was hidden from view. During foraging, cranes interrupt feeding bouts with short vigilance bouts (standing and scanning the surroundings) of only a few seconds (e.g. Alonso and Alonso 1993) and short bouts of walking while searching for food (for a description of foraging behaviour see e.g. Johnsgard 1983, Meine and Archibald 1996). Therefore, we recorded focal birds as foraging when 
they were recorded picking or digging at the sample point or within an estimated 15 seconds after standing or walking (for behaviour classes in studies on cranes, see e.g. Alonso et al. 1986, Eguchi et al. 1991, Alonso and Alonso 1992, 1993, Pae and Won 1994, Fox et al. 1995, Nowald 1995, Melo et al. 1999, Wilkening 1999).

Location of a bird was determined by taking a compass bearing of the focal bird simultaneously from two observation points. Accuracy of the compasses was $\pm 1^{\circ}$ to $\pm 2^{\circ}$. Bearings were corrected for magnetic deviation with data obtained from Sukhbaatar et al. (2002). GPS coordinates of observation points were recorded and locations of focal birds determined by triangulation in the software program Tracker 1.I (Tracker Radio Location System, Stockholm, Sweden).

\section{Habitat recording}

Habitat characteristics of areas used by three pairs during focal bird observations were recorded in August at sampling points on a 100-200 m grid (depending on the size of the area sampled). We recorded vegetation height (averaged over three samples), ground condition (dry, moist or height of standing water) and whether or not the area was dominated by wetland vegetation (Cyperaceae, Juncaceae, reed). Later, vegetation height was grouped into two categories, 20-50 $\mathrm{cm}$ and $>50 \mathrm{~cm}$. Ground condition was grouped into the categories dry or moist/flooded.

\section{Data analysis}

Locations of focal birds were plotted using the software program Tracker and the area used per pair and per observation day calculated using a minimum convex polygon (White and Garrot 1990). When two distinct areas were used, two minimum convex polygons were constructed and their respective areas summed. Sample points for which we could not plot a location of a focal bird did occur (e.g. focal bird hidden behind some willow bushes). When the focal bird was located inside the area covered by the minimum convex polygon (e.g. an area hidden by willow bushes known to be inside the polygon), the observation day was retained. Otherwise the observation day was omitted. When the angle between the two bearings was small $\left(<30^{\circ}\right)$, the triangulated location of the focal bird was considered to be not sufficiently accurate and the observation day was also omitted. Sixteen observation days of six pairs with juveniles and three observation days of three pairs without juveniles were retained in the analysis. The furthest distance from the roosting-site to any location of a focal pair or pair partner during an observation day was also calculated.

Weather conditions strongly influenced the length of time over which we were able to observe crane behaviour during dawn and dusk. We defined the daylight period of an observation day as the period between sunrise and sunset (as recorded in the field) and time budget is given as a percentage of the daylight period. Preening and resting as well as "out of sight" recordings during the daylight period in which the focal birds were known to be at the roosting-site were grouped into preening/resting. Observation days with more than $5 \%$ "out of sight" recordings during the daylight period were omitted from the time budget analysis. In 2000, 12 and, in 2001, 17 observation days of five pairs with juveniles were retained. Three observation days of three pairs without juveniles in 2000 were retained. In contrast, behaviour patterns are presented including recordings during dawn and dusk and including observation days of pairs with more than $5 \%$ 'out of sight' recordings. Behaviour patterns are presented for ten parental and six nonparental pairs.

To avoid problems of statistical independence of proportional data (unit-sum constraint), time budget data were analysed using compositional analysis (Aebischer and Robertson 1992, Aebischer et al. 1993). Zero proportions were replaced with values an order of magnitude less (o.0001) than the lowest observed proportions (Aebischer et al. 1993) and log-ratios calculated. GLM was used to test for year differences in time budget (Quinn and Keough 2002). 


\section{Results}

\section{Time budgets}

The main behaviour category recorded during the daylight period was foraging (Table 1 , Figure 2). Parental cranes spent $79.6 \pm 4.8 \%$ (Io pairs, 2000 and 2001) of the daylight period foraging whereas pairs without juveniles spent only $60.3 \pm 14.0 \%$ (three observation days of three pairs) of the daylight period foraging. We found no difference in time budget for parental cranes between 2000 and 2001 (Wilk's lambda, $F=0.16, P=0.96$ ). Foraging time shows a slight but non-significant increase with chick age during the second and third week $\left(r_{s}=0.40, P=0.58\right)$ (Figure 3). Preening/resting was recorded during $4.4 \pm 1.9 \%$ of the daylight period for parental pairs and during $24.3 \pm 11.1 \%$ of the daylight period for non-parental cranes.

Foraging behaviour also determined the overall daylight activity pattern (Figure 2). Whereas pairs without chicks showed a bimodal foraging activity pattern, we did not find any distinct diurnal patterns of behaviour for pairs with chicks. Pairs without juveniles sometimes went to a shallow water body during midday for a period of resting and preening which we did not observe in parental cranes. With shorter days and older juveniles, pairs increasingly left the roosting-site before sunrise $\left(r_{s}=0.78, P<0.001\right)$ and returned after sunset $\left(r_{s}=0.53, P=0.006\right)$ (Figure 4$)$.

\section{Habitat use}

The size of the area used by crane families ranged from 11 to 155 ha per day (Table 2). Pairs rearing juveniles used on average $65 \pm 31$ ha per day, pairs without juveniles $111 \pm 35$ ha per day.

Two pairs used a composite area of 165 and 379 ha, respectively, during observation days with chicks aged $c .15,30,55$ and 65 days (see Figure 5 for an example of one pair). Maximum recorded distance of a focal parental bird from the roosting-site was 3,030 $\mathrm{m}$.

Start and finish of daily movements was always the roosting-site. Five pairs retained their nest-site at the periphery of their minimum convex polygon (e.g. Figure 5). The sixth pair permanently moved to another wetland about $2 \mathrm{~km}$ from the nest-site, probably because the wetland adjacent to the nest-site was too small to provide enough foraging habitat for the family.

The habitat grids sampled ( 72 points) covered more than $80 \%$ of the minimum convex polygon of five observation days of three pairs. The majority of grid points were dominated by wetland vegetation $(76-100 \%)$ in the $20-50 \mathrm{~cm}$ height class $(72-94 \%)$. The majority of habitat points for two pairs were dry $(83 \%$ and $94 \%, n=45)$ while only $33 \%$ of habitat points of the third pair were dry $(n=27)$.

Table 1. Time budget of White-naped Crane pairs in north-eastern Mongolia between sunrise and sunset.

\begin{tabular}{|c|c|c|c|c|c|c|}
\hline \multirow[t]{3}{*}{ Behaviour category } & \multicolumn{4}{|l|}{2000} & \multirow{2}{*}{\multicolumn{2}{|c|}{$\frac{2001}{\text { With juveniles }}$}} \\
\hline & \multicolumn{2}{|c|}{ Without juveniles } & \multicolumn{2}{|l|}{ With juveniles } & & \\
\hline & $\begin{array}{l}\text { Mean } \pm \text { SD } \\
(n=3 \text { pairs })\end{array}$ & $\begin{array}{l}\text { Min.-Max. } \\
(n=3 \\
\text { obs-d })\end{array}$ & $\begin{array}{l}\text { Mean } \pm \text { SD } \\
(n=5 \text { pairs })\end{array}$ & $\begin{array}{l}\text { Min.-Max. } \\
(n=12 \\
\text { obs-d })\end{array}$ & $\begin{array}{l}\text { Mean } \pm \text { SD } \\
(n=5 \text { pairs })\end{array}$ & $\begin{array}{l}\text { Min.-Max. } \\
(n=17 \\
\text { obs-d })\end{array}$ \\
\hline Foraging (\%) & $60.3 \pm 14.0$ & $41.0-73.6$ & $81.1 \pm 4.5$ & $63.2-93.7$ & $78.1 \pm 4.8$ & $63.9-88.2$ \\
\hline Standing (\%) & $5.8 \pm 3.5$ & $2.3-10.7$ & $5.1 \pm 2.7$ & $0.6-16.8$ & $7 \cdot 3 \pm 2.4$ & $0.0-14 \cdot 7$ \\
\hline Preening/resting (\%) & $24 \cdot 3 \pm 11.1$ & $14.6-39.9$ & $5.0 \pm 2.0$ & $0.0-12.9$ & $3.7 \pm 1.5$ & $0.5-6.4$ \\
\hline Locomotion (\%) & $7 \cdot 3 \pm 2.8$ & $4.6-11.2$ & $6.3 \pm 1.7$ & $0.5-14.3$ & $6.2 \pm 1.8$ & $1.6-11.8$ \\
\hline Other $(\%)$ & $2.3 \pm 0.9$ & $1.1-3.4$ & $0.8 \pm 0.4$ & $0.0-2.4$ & $4.3 \pm 1.4$ & $0.0-9.8$ \\
\hline Out of sight (\%) & $0.0 \pm 0.0$ & 0.0-0.0 & $1.7 \pm 0.8$ & $0.0-4.7$ & $0.4 \pm 0.5$ & $0.0-4.1$ \\
\hline
\end{tabular}

Mean \pm SD are percentages of the daylight period for pairs with juveniles and pairs without juveniles. obs-d number of observation days. 

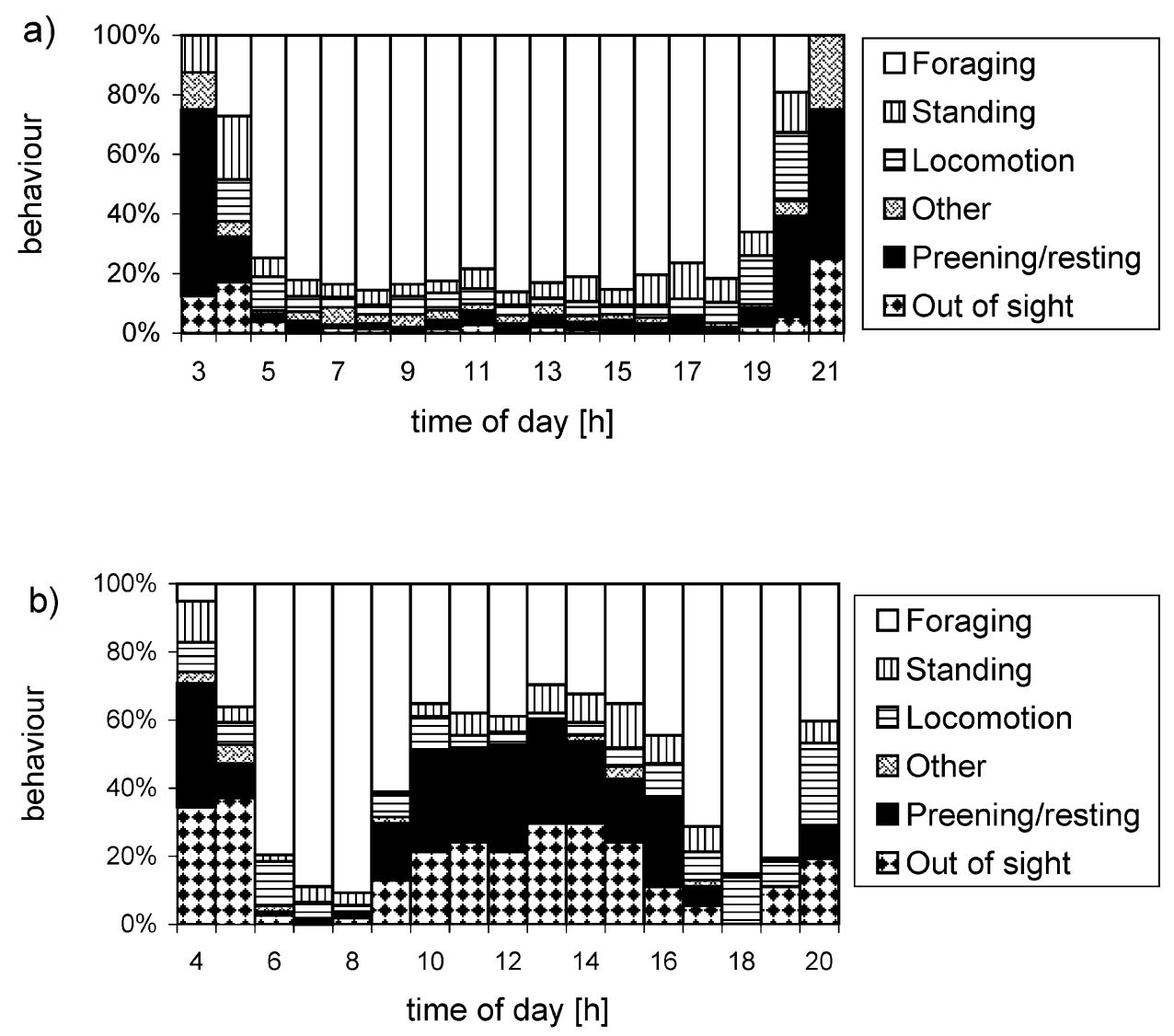

Figure 2. Diurnal behaviour patterns of White-naped Cranes in north-eastern Mongolia. (a) Pairs with chicks in 2000 and 2001 (10 pairs, 29 observation days); (b) pairs without chicks in 2000 (six pairs, 9 observation days). Time is GMT +8 hours.

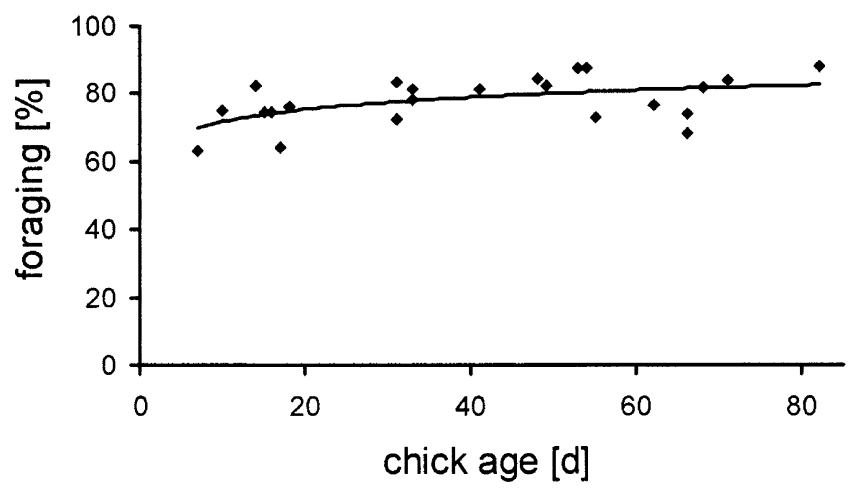

Figure 3. Foraging as a percentage of the daylight period (between sunrise and sunset) for pairs with chicks of known ages (six observation days of two pairs in 2000, 17 observation days of five pairs in 2001). 

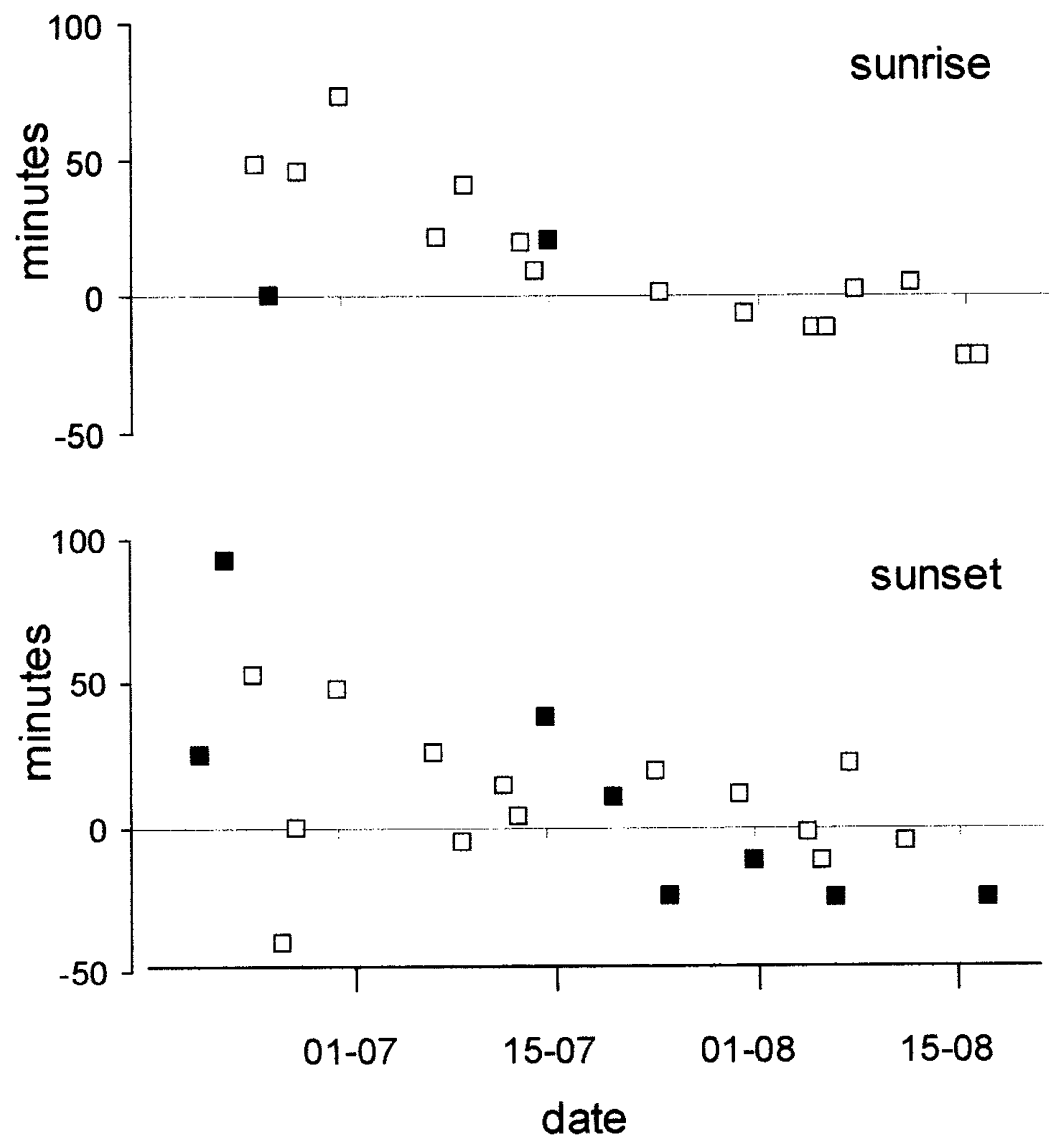

Figure 4. Departure and arrival of parental White-naped Crane pairs from and at the roostingsite in relation to sunrise $\left(r_{s}=0.78, P<0.001\right)$ and sunset $\left(r_{s}=0.53, P=0.006\right)$. Filled squares, 2000; unfilled squares, 2001.

Table 2. Size of area used, and maximum distances between feeding and roosting sites, of White-naped Crane pairs with and without juveniles in north-eastern Mongolia.

\begin{tabular}{lll}
\hline & Mean \pm SD & Min.-Max. \\
\hline $\begin{array}{l}\text { Size of area } \\
\text { Pairs with juveniles (14-c. 80 days) }\end{array}$ & $65 \pm 31$ ha (6 pairs) & $11-155$ ha (16 obs-d) \\
$\begin{array}{l}\text { Pairs without juveniles } \\
\text { Maximum distance }\end{array}$ & $111 \pm 35$ ha (3 pairs) & $62-144$ ha (3 obs-d) \\
$\begin{array}{l}\text { Pairs with juveniles (14-c. 80 days) } \\
\text { Pairs without juveniles }\end{array}$ & $1209 \pm 442 \mathrm{~m}$ (6 pairs) & $360-3,030 \mathrm{~m}$ (16 obs-d) \\
\hline
\end{tabular}

obs-d number of observation days. 


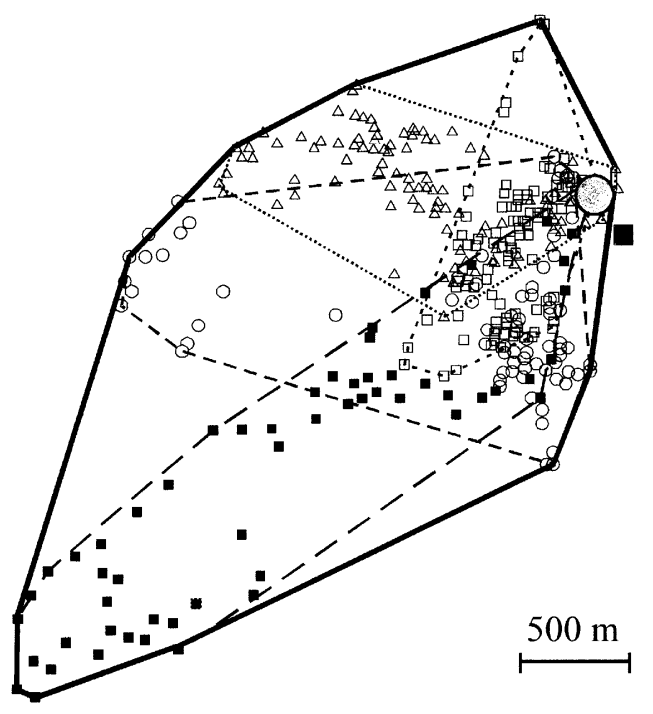

Figure 5. Typical example of the area used by a White-naped Crane family during four observation days in north-eastern Mongolia with one chick aged 17 days (unfilled squares), 33 days (filled squares), 55 days (circles) and 66 days (triangles). Respective minimum convex polygons and a composite minimum polygon are shown. Circle: roosting-site; large square: nestsite.

\section{Discussion}

\section{Time budgets}

Behaviour patterns of non-parental White-naped Crane pairs in the Ulz river valley show a typical bimodal activity pattern with two foraging peaks, in the morning and in the afternoon (Figure 2). Foraging times are separated by a quite pronounced peak in preening and resting activity during midday. The peak in 'out of sight' recordings at midday reflects the fact that pairs often chose a hidden place in a shallow water body for the midday break. Both the time budgets in total $24 \%$ of preening and resting activity - and the behaviour patterns indicate that Whitenaped Cranes without chicks were not time-stressed to meet their daily energy demands. Oversummering Eurasian Cranes in Germany show a very similar pattern in feeding activities (Wilkening 1999). Preening was $17 \%$ in oversummering Eurasian Cranes (Wilkening 1999), $17 \%$ in birds overwintering in Portugal (Melo et al. 1999), 10\% in parental wintering birds and $15 \%$ in non-parental wintering birds in Spain (Alonso and Alonso 1993).

In contrast, a period of comfort behaviour between sunrise and sunset was totally absent in parental White-naped Cranes (Figure 2). Preening and resting behaviour was reduced to only 4.4 $\pm 1.9 \%$. Nowald (2001) found a similar value of $4.8-6.9 \%$ preening behaviour in Eurasian Crane families during the breeding period. Foraging as recorded in this study (see Methods) encompasses all activities related to feeding (searching, handling and eating food) and also short vigilance (standing) bouts. Alonso and Alonso (1993) and Nowald (2001) found higher vigilance levels in parental than in non-parental Eurasian Cranes. High foraging levels by parental birds $(80 \%)$ in our study are therefore likely to be caused partly by high vigilance levels.

Focal parent birds in our study had reduced comfort behaviour between sunrise and sunset to a minimum. They might be able to expand their foraging time by making increased used of dawn and dusk. However, during the later stages of the chick-rearing period, focal parent birds already 
made use of dawn and dusk (Figure 4) and it is unlikely that a significant further increase could be achieved. A further increase in feeding-related activities could probably only be achieved by reducing parental vigilance. Conversely, increased levels of vigilance due to disturbance could probably only be achieved at the expense of feeding-related activities.

Slow-moving herds of grazing animals did not cause visible alarm unless approaching the roosting-site while cranes were there. Focal birds were usually not recorded near grazing livestock herds and we assume that cranes avoided their close proximity. This could potentially exclude them from good foraging habitat and be a considerable problem in areas with many herds or if livestock numbers in Mongolia increase further (e.g. Oyun-Erdene 1998). Identified causes for alarm of parent cranes were horsemen, carts, cars, fast-moving livestock herds, dogs, Grey Wolves (Canis lupus) and Eurasian Cranes or other White-naped Cranes. Considerable alarm was caused by horsemen who passed close to White-naped Crane families. In one family, chick and parents were separated for up to $1.5 \mathrm{~h}$ by a passing horseman. Some of the lowest proportions of foraging time were recorded for this family in an area frequented by horsemen. Repeated disturbance of this level could lead to insufficient energy intake and consequently to reduced reproductive success. Effects of time-constrained feeding activities on reproductive success need not necessarily become obvious in the breeding areas. Juveniles in better body condition might have higher chances of surviving migration (e.g. Cam et al. 2003).

\section{Habitat use}

Parental White-naped Cranes in the Ulz river valley used a daily area of $65 \pm 31$ ha and two pairs used a composite area of 165 and 379 ha, respectively, during four observation days. For a Eurasian Crane family, Nowald (1999) gives 68.9 and 38 ha as the maximum area used per day by a family during two breeding seasons and 103 and 77 ha, respectively, for the composite area. McMillen (in Baker et al. 1995) found an average home range for Sandhill Crane chicks of 157.9 ha with a core area of 55 ha.

Fujita et al. (1994) found that White-naped Cranes prefer wet steppe areas (of which the Ulz river valley is part). Within this climate type, foraging areas of White-naped Cranes include wetlands, adjacent grasslands and cropland (Meine and Archibald 1996). Our observations show that foraging largely took place in wetland; however, large parts of the daily area used by two out of three pairs were dry. Although a few wet microhabitat features were present in these areas, the plots of focal bird locations (Figure 5) do show a widespread use of the area rather than concentrations of points. This indicates that the wide areas of dry habitats were used for foraging. However, the study took place during years of severe droughts occurring in consecutive summers from 1999 onwards (Iwao and Takahashi 2006) and many temporarily flooded areas had already disappeared by the time the chicks had hatched (pers. obs.). If shallow flooded areas had been available to a greater extent, then they might possibly be preferred for foraging by White-naped Cranes (e.g. during an observation day of an incubating pair, a shallow flooded area of only $<0.25$ ha was used during $42 \%$ of the time the focal bird was visible).

\section{Management implications}

Many herdsmen can identify White-naped Cranes and know if they have a pair or family in the vicinity. White-naped Cranes can usually be seen from a distance when on horseback. It would require relatively little effort for horsemen to avoid getting too close to a White-naped Crane family and they might willingly do so if made aware of the disturbance caused.

White-naped Cranes prefer wet areas with high nest concealment and low grazing pressure as nest-sites (Bradter et al. 2005) and grazing animals should therefore be kept out of potential nest-sites (i.e. flooded areas and ponds within the breeding area). In foraging areas, White-naped Cranes avoided the proximity of livestock herds and the presence of many herds might leave 
them with insufficient foraging habitat. Slow-moving herds did not visibly alarm the cranes and livestock grazing up to a certain stocking density might not be detrimental, and might even be beneficial. We do not know whether livestock grazing itself has a positive or negative effect on food availability or accessibility (e.g. by reducing vegetation height) and these questions need to be answered before recommendations on grazing in White-naped Crane foraging areas can be given. Maximum distance of a focal animal from the roosting-site was 3,030 $\mathrm{m}$. If targeted measures for the protection of the White-naped Crane are to be implemented, they should be focused within c. $3 \mathrm{~km}$ of the roosting-site and nest-site. If roosting and nest-sites are not known or if management is to be extended to areas which are presently unoccupied, measures should be focused within $c .3 \mathrm{~km}$ of flooded areas as flooded areas are potential nest- and roosting-sites.

\section{Acknowledgements}

We thank BP Conservation Programme, Stiftung Würth, Stifterverband für die Deutsche Wissenschaft, Southern Helicopters, Jonna Inc., DBA Classics, Mississippi Coast Audubon Society, Mississippi Coast chapter of the Sierra Club, J. and D. Bird, H. and J. Briggs, Mr and Mrs P. B. Cooper, J. Dubuisson, A. Duckett, G. Dunbar, M. Fahnestock, R. H. Goodwin, J. and G. Grazia, A. Henry, A. and W. Hornkohl, B. M. Kelly, E. and I. Methe, G. Morgan, M. Page, M. Peacock, The Perrettis, B. Schaffler, B. and E. Schaffler, E. Thompson and M. Woodrey for funding. The Protected Area Administration of Eastern Mongolia and the UNDP Eastern Steppe Biodiversity Project in Choibalsan offered valuable advice and logistical support. Plant species were identified by B. Oyuntsetseg and Ch. Dulamsuren. S. Davaakhuu and Saranchimeg assisted in the field. We are grateful for support and advice in the field to Dolgormaa and Bazarbaani, C. Ketzenberg and J. Leyrer, the rangers and our drivers, especially Deriilaa, Chimedseren, Baldshinjam, Chimbat and Lkhagvaa, and all Ulz river inhabitants for their hospitality and logistical support. We thank G. Nowald (Kranichschutz Deutschland - NABU, WWF, Lufthansa) for co-operation, U. van Elsberg for help with the figures and F. Bairlein, A. Bräunlich and S. J. Marsden for comments on an earlier draft of the manuscript.

\section{References}

Aebischer, N. J. and Robertson, P. A. (1992) Practical aspects of compositional analysis as applied to pheasant habitat utilisation. Pp. 285-293 in I. G. Priede and S. M. Swift, eds. Wildlife telemetry: Remote monitoring and tracking of animals. Chichester, U.K.: Ellis Horwood.

Aebischer, N. J., Robertson, P. A. and Kenward, R. E. (1993) Compositional analysis of habitat use from animal radiotracking data. Ecology 74: 1313-1325.

Alonso, J. C. and Alonso, J. A. (1992) Daily activity and intake rate patterns of wintering common cranes Grus grus. Ardea 80: $343-351$.

Alonso, J. A. and Alonso, J. C. (1993) Agerelated differences in time budgets and parental care in wintering Common Cranes. Auk 110: 78-88.

Alonso, J. A., Veiga, J. P. and Alonso, J. C. (1986) Time budgeting and social structure of Common Cranes Grus grus wintering in Iberia. Ricerche di Biologia della Selvaggina 10: 1-14.

Anonymous (1998) North East Asian Crane Site Network Newsletter Volume1, Number 1. www.wing-wbsj.or.jp

BirdLife International (2001) Threatened birds of Asia: The BirdLife International Red Data Book. Cambridge, U.K.: BirdLife International.

BirdLife International (2003) Saving Asia's threatened birds: A guide for government and civil society. Cambridge, U.K.: BirdLife International.

BirdLife International (2004) Important Bird Areas in Asia: Key sites for conservation. Cambridge, U.K.: BirdLife International. 
Bold, A., Tseveenmyadag, N. and Zvonov, B. M. (1995) Cranes of Mongolia. Pp. 42-47 in C. H. Halvorson, J. T. Harris and S. M. Smirenski, eds. Cranes and storks of the Amur Basin: The proceedings of the international workshop, 3-12 July 1992. Moscow: Arts Literature Publishers.

Bradter, U., Gombobaatar, S., Uuganbayar, C. h., Grazia, T. G. and Exo, K.-M. (2005) Reproductive performance and nest-site selection of White-naped Cranes Grus vipio in the Ulz river valley, north-eastern Mongolia. Bird Conserv. Int. 15: 313-326.

Cam, E., Monnat, J.-Y. and Hines, J. E. (2003) Long-term fitness consequences of early condition in the Kittiwake. J. Anim. Ecol. 72: 411-424.

Dugintsov, V. A. and Pankin, N. S. (1995) Antropic "micropopulations" - a chance of survival for Red-crowned and White-naped Cranes. Pp. 332-333 in H. Prange, ed. Crane research and protection in Europe. Halle-Wittenberg, Germany.

Eguchi, K., Nagata, H., Takeish, M., Henmi, Y. and Takatsuka, M. (1991) Foraging and time budget of the Hooded Cranes in a wintering area at Yashiro, Japan. Pp. 305-310 in J. Harris, ed. Proceedings of the 1987 International Crane Workshop. Baraboo, USA.

Exo, K.-M. (1992) Methoden zur Aufnahme von Raum-Zeit-Budgets bei Vögeln, dargestellt am Beispiel des Austernfischers (Haematopus ostralegus). Vogelwarte 36: 311-325.

Fisher, I. J. and Swengel, S. R. (I991) A guide for aging Sandhill Crane eggs. Wildl. Soc. Bull. 19: 494-497.

Fox, A. D., Boyd, H. and Bromley, R. G. (1995) Diurnal activity budgets of prenesting Sandhill Cranes in arctic Canada. Wilson Bull 107: 752-756.

Fujita, G., Harris, J., Bold, A., Tseveenmyadag, N. and Chuluunbaatar, S. (1994) Habitat preference of Demoiselle and White-naped Cranes, Anthropoides virgo and Grus vipio breeding in Mongolia. Pp. 93-96 in H. Higuchi and J. Minton, eds. The Future of cranes and wetlands. Tokyo, Japan.

Gombobaatar, S. (2002a) Biology-ecological studies of White-naped Crane (Grus vipio) in the Onon and $\mathrm{Ulz}$ river basins, Mongolia. Pp. 45-47 in D. Pegdel and Z. Enkh-Amgalan, eds. Proceedings of the First Conference of Young Scientists in Mongolia. Ulaanbaatar, Mongolia.

Gombobaatar, S. (2002b) Cranes of the Onon and Ulz river basins. J. Mongolian Birds, Amphibians and Reptiles 1: 90-109 (in Mongolian).

Gombobaatar, S. and Sumiya, D. (1998) Protection of cranes in Mongolia. National University of Mongolia Scientific Journal Biology 7: 45-55 (in Mongolian).

Goroshko, O. (2002) The status of crane populations in Transbaikalia and the adjacent territories. Crane Working Group of Eurasia Newsletter 4-5: 38-40.

Goroshko, O. and Tseveenmyadag, N. (2001) White-naped Crane in south-eastern Transbaikalia and north-eastern Mongolia. Pp. 522-529 in E. Kurochkin and I. Rakchimov, eds. Achievements and problems of ornithology of northern Eurasia on a boundary of centuries. Magarif Publishers, Kazan (in Russian with English summary).

Goroshko, O. and Tseveenmyadag, N. (2002) Status and conservation of Cranes in Daurian Steppes (Russia and Mongolia). China Crane News 6: 5-7.

IUCN (2006) IUCN Red List of Threatened Species. www.iucnredlist.org (downloaded on 18 September 2006).

Iwao, K. and Takahashi, M. (2006) Interannual change in summertime precipitation over northeast Asia. Geophys. Res. Lett. 33, L16703 doi:10.1029/ 2006GLo27119.

Johnsgard, P. A. (1983) Cranes of the world. Bloomington, Indiana: Indiana University Press.

Li Chunyuan, Pan Weili and Chao Yupu. (1991) Behaviour of the White-naped Crane. Pp. $61-62$ in J. Harris, ed. Proceedings of the 1987 International Crane Workshop. Baraboo, USA.

Li Peixun, Li Fangman and Yu Xuefeng. (1991) Selection of nesting sites and territories by White-naped Cranes in Lindian county, China. Pp. 59-6o in J. Harris, ed. Proceedings of the 1987 International Crane Workshop. Baraboo, USA. 
Martin, P. and Bateson, P. (1986) Measuring behaviour: An introductory guide. Cambridge, U.K.: Cambridge University Press.

Meine, C. D. and Archibald, G. W. (1996) The Cranes: Status survey and conservation action plan. Gland, Switzerland: IUCN.

Melo, M. P., Almeida, J., Vaz, A. and Covas, R. (1999) The daily activity of wintering Common Cranes Grus grus in Portugal: the effect of scarce food resources. Vogelwelt 120: 353-356.

McMillen, J. L. (1988) Productivity and movements of the Greater Sandhill Crane population at Seney National Wildlife Refuge: potential for an introduction of Whooping Cranes. PhD thesis. In: B. W. Baker, B. S. Cade, W. L. Mangus and J. L. McMillen. (1995) Spatial analysis of Sandhill Crane nesting habitat. J. Wildl. Manage. 59: 752-758.

Nowald, G. (1995) Zeitliche und räumliche Habitatnutzung einer Frühjahrspopulation des Kranichs Grus grus in der BockRegion. Pp. 537-547 in H. Prange, ed. Crane research and protection in Europe. Halle-Wittenberg, Germany.

Nowald, G. (1999) Reviergrösse und Raumnutzung jungeführender Kraniche Grus grus in Mecklenburg-Vorpommern: Erste Ergebnisse einer Telemetriestudie. Vogelwelt 120: 261-274.

Nowald, G. (2001) Verhalten von Kranichfamilien (Grus grus) in Brutrevieren Nordostdeutschlands: Investition der Altvögel in ihre Nachkommen. J. Ornithol. 142: 390-403.

Oyun-Erdene, N. (1998) Issues of wetland and pasture management. Pp. $46-58$ in Proceedings of the International Workshop on Wetland Conservation in Mongolia and North-East Asia, Ulaanbaatar.

Pae, Seong-Hwan and Won, Pyong-Oh (1994) Wintering ecology of Red-crowned Cranes and White-naped Cranes Grus japonensis and G. vipio in the Cholwon
Basin, Korea. Pp. 97-106 in H. Higuchi and J. Minton, eds. The future of cranes and wetlands. Tokyo, Japan.

Quinn, G. P. and Keough, M. J. (2002) Experimental design and data analysis for biologists. Cambridge, U.K.: Cambridge University Press.

Smirenski, S. M. (1999) Crane protection, environmental education and sustainable development in rural areas of the Russian Far East. Pp. 323-327 in H. Prange, G. Nowald and W. Mewes, eds. Proceedings of the Third European Crane Workshop. Halle-Wittenberg, Germany.

Sukhbaatar, S., Gunchin-Ish, Tsegmid, B., Bayanjargal, G., Amarjargal, B., Mungunshagai, T., Onkhloi, T., Davaasambuu, A., Nasan-Ochir, T. and Byambaa, S. (2002) GEOMAGNETIC. Unpublished report.

Su Liying, Xu Jie and Zhou Desheng. (1991) Breeding habits of White-naped Cranes at Zhalong Nature Reserve, China. Pp. 51-57 in J. Harris, ed. Proceedings of the 1987 International Crane Workshop. Baraboo, USA.

Tseveenmyadag, N. and Goroshko, O. (2001) Some results of studies on reproduction and autumn migration of rare cranes in eastern Mongolia. Ecosystem of Eastern Mongolia: 56-63 (in Mongolian).

White, G. C. and Garott, R. A. (1990) Analysis of wildlife radio-tracking data. San Diego, U.S.A.: Academic Press.

Wilkening, B. (1999) Verhalten und Habitatwahl einer übersommernden Nichtbrüter-Population des Kranichs Grus grus in der Agrarlandschaft. Pp. 58-63 in H. Prange, G. Nowald and W. Mewes, eds. Proceedings of the Third European Crane Workshop. Halle-Wittenberg, Germany.

Yuan Tao and Li Peixun. (1991) Observations on mating behaviour of White-naped Cranes in the wild. Pp. 63-65 in J. Harris, ed. Proceedings of the 1987 International Crane Workshop. Baraboo, USA. 
SUNDEV GOMBOBAATAR, CHULUUNBAATAR UUGANBAYAR

Department of Zoology, National University of Mongolia, P. O. Box 537, Ulaanbaatar 210646A, Mongolia.

TRACY E. GRAZIA

Mississippi Sandhill Crane National Wildlife Refuge, 7200 Crane Lane, Gautier, MS 39553, U.S.A.

*Author for correspondence.e-mail:verandering@gmx.de

Received 14 February 2006; revision accepted 31 October 2006 